\title{
$\mathbf{J}|\mathbf{A}| \mathbf{C} \mid \mathbf{S}$ \\ $\overline{\text { COMMUNICATIONS }}$
}

Published on Web 05/21/2002

\section{Formation of Alkylsilane-Based Monolayers on Gold}

\author{
Thomas M. Owens, Kenneth T. Nicholson, Mark M. Banaszak Holl, ${ }^{*}$ and Sefik Süzer ${ }^{\dagger}$ \\ Department of Chemistry, The University of Michigan, Ann Arbor, Michigan 48109-1055
}

Received January 30, 2002

Modification of metal surfaces through the adsorption of small molecules has been used to alter the adhesion, corrosion, lubrication, ${ }^{1}$ and wetting ${ }^{2}$ properties of metals. Self-assembled monolayers (SAMs) of alkanethiols on gold ${ }^{3}$ have been studied extensively in this regard. ${ }^{4}$ The ability to vary alkane chain lengths and end groups ${ }^{5}$ has made them valuable for extending the fundamental understanding of surface phenomena.

Expansion of the variety of chemistry possible at the interface would greatly enhance efforts to achieve the wide-ranging promises of this technology. It has been demonstrated that silane will chemisorb to several clean metal surfaces ${ }^{6}$ and alkylsilanes have been used to modify oxidized surfaces. ${ }^{7}$ Recently, $\mathrm{H}_{8} \mathrm{Si}_{8} \mathrm{O}_{12}$ was reported to chemisorb on clean gold surfaces at $20{ }^{\circ} \mathrm{C}$ via a novel $\mathrm{Si}-\mathrm{H}$ activation. ${ }^{8}$ These discoveries set the stage for the synthesis of a new class of alkylsilane-based monolayers.

Chemisorbed monolayers of $n$-hexylsilane $\left(\mathrm{H}_{13} \mathrm{C}_{6} \mathrm{SiH}_{3}\right), n$ octylsilane $\left(\mathrm{H}_{17} \mathrm{C}_{8} \mathrm{SiH}_{3}\right)$, and $n$-octadecylsilane $\left(\mathrm{H}_{37} \mathrm{C}_{18} \mathrm{SiH}_{3}\right)$ are formed by exposing freshly evaporated gold surfaces to saturating doses ( $>440 \mathrm{~L}, 1 \mathrm{~L}=1 \times 10^{-6}$ Torr $\left.\cdot \mathrm{s}\right)$ of one of these alkylsilanes in an ultrahigh vacuum (UHV) chamber. The samples have been characterized in UHV by reflection-absorption infrared spectroscopy (RAIRS) and X-ray photoelectron spectroscopy (XPS).

The RAIRS spectra of the octyl- and hexylsilane monolayers (Figure 1, B and $\mathrm{C}$ ) each exhibit four $v(\mathrm{C}-\mathrm{H})$ vibrational modes. The peak frequencies and vibrational mode assignments for the octylsilane-based layer are the following: $v_{\mathrm{s}}\left(\mathrm{CH}_{2}\right) 2856 \mathrm{~cm}^{-1}, v_{\mathrm{s}^{-}}$ $\left(\mathrm{CH}_{3}\right) 2879 \mathrm{~cm}^{-1}, v_{\mathrm{a}}\left(\mathrm{CH}_{2}\right) 2925 \mathrm{~cm}^{-1}$, and $v_{\mathrm{a}}\left(\mathrm{CH}_{3}\right) 2967 \mathrm{~cm}^{-1}$ (Figure 1B). For the hexylsilane layer, the features are observed at $v_{\mathrm{s}}\left(\mathrm{CH}_{2}\right) 2850 \mathrm{~cm}^{-1}$ (observed as a shoulder), $v_{\mathrm{s}}\left(\mathrm{CH}_{3}\right) 2879 \mathrm{~cm}^{-1}$, $v_{\mathrm{a}}\left(\mathrm{CH}_{2}\right) 2925 \mathrm{~cm}^{-1}$, and $v_{\mathrm{a}}\left(\mathrm{CH}_{3}\right) 2964 \mathrm{~cm}^{-1}$ (Figure 1C). The spectrum of chemisorbed octadecylsilane (Figure 1A) contains only three features in the $v(\mathrm{CH})$ region: $v_{\mathrm{s}}\left(\mathrm{CH}_{2}\right) 2850 \mathrm{~cm}^{-1}, v_{\mathrm{a}}\left(\mathrm{CH}_{2}\right)$ $2923 \mathrm{~cm}^{-1}$, and $v_{\mathrm{a}}\left(\mathrm{CH}_{3}\right) 2968 \mathrm{~cm}^{-1}$. A direct comparison to the solution IR spectrum of octylsilane (Figure 1D) illustrates the absence of the prominent $v(\mathrm{Si}-\mathrm{H})$ at $2150 \mathrm{~cm}^{-1}$ from RAIRS spectra for the silane-based layers.

Soft X-ray photoelectron spectroscopy data are summarized in Table 1. The Si $2 p$ core-level spectra (Figure 2B) have been obtained (photon energy, $h v=160 \mathrm{eV}$ ) and consist of a spinorbit doublet $\left(2 \mathrm{p}_{3 / 2}\right.$ and $\left.2 \mathrm{p}_{1 / 2}\right)$ with binding energies of $-99.8 \mathrm{eV}$ and $-100.4 \mathrm{eV}$ and full width at half-maximum (fwhm) of $0.4 \mathrm{eV}$ for each of the chemisorbed layers. The Au $4 \mathrm{f}$ core-levels for a clean gold suface are included for reference (Figure 2B, 4). A single $\mathrm{C} 1 \mathrm{~s}(h v=342.5 \mathrm{eV})$ feature is observed at $-285 \mathrm{eV}$ (Figure 2A). The area ratio of $6: 8: 12$ observed for the $\mathrm{C} 1 \mathrm{~s}$ silane data is the same as that detected for thiol-based SAMs when no correction for the attenuation of the photoelectrons through the alkane chains is made. ${ }^{9}$ Contrary to many thiol-based SAMs, ${ }^{10}$ no changes in the

\footnotetext{
* Corresponding author. Email: mbanasza@umich.edu.

$\dagger$ Permanent address: Chemistry Department, Bilkent University, 06533 Ankara, Turkey.
}

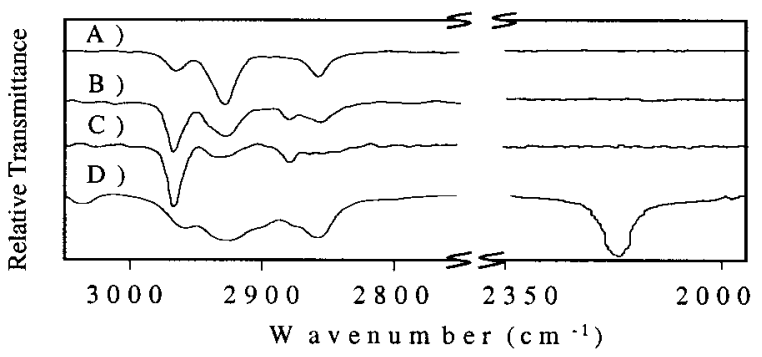

Figure 1. RAIRS data (3050-2750 and $\left.2350-2000 \mathrm{~cm}^{-1}\right)$ for monolayers of (A) octadecylsilane, (B) octylsilane, and (C) hexylsilane on Au. The RAIRS spectra represent $\sim 3000$ scans at $8 \mathrm{~cm}^{-1}$ resolution ratioed to a clean gold background. A solution IR spectrum of octylsilane (D) is included for comparison.

Table 1. Selected Curve Fitting Parameters for Core-Level XPS Data

\begin{tabular}{|c|c|c|c|}
\hline parameter & $\mathrm{H}_{13} \mathrm{C}_{6} \mathrm{SiH}_{3}$ & $\mathrm{H}_{17} \mathrm{C}_{8} \mathrm{SiH}_{3}$ & $\mathrm{H}_{37} \mathrm{C}_{18} \mathrm{SiH}_{3}$ \\
\hline Si $2 p_{3 / 2}$ B.E. $(e V)$ & -99.7 & -99.8 & -99.8 \\
\hline Si $2 p$ fwhm $(e V)$ & 0.4 & 0.4 & 0.4 \\
\hline C 1 s B.E. $(\mathrm{eV})$ & -284.7 & -284.9 & -285.0 \\
\hline C 1s fwhm (eV) & 1.2 & 1.2 & 1.1 \\
\hline C 1s area & 2.2 & 2.9 & 4.5 \\
\hline rel. C $1 \mathrm{~s}$ area ratio ${ }^{a}$ & 6 & 8 & 12 \\
\hline
\end{tabular}

${ }^{a}$ Ratio calculated by setting the hexylsilane $\mathrm{C} 1 \mathrm{~s}$ area equal to six carbons.

Si $2 \mathrm{p}, \mathrm{C} 1 \mathrm{~s}$, and valence band region $(h v=160 \mathrm{eV})$ are detected after more than $24 \mathrm{~h}$ of irradiation.

Only features originating from the $\mathrm{Au} 5 \mathrm{~d}$ and $\mathrm{Au} 6 \mathrm{~s}$ levels are observed in the valence band region for a clean gold surface (Figure $2 \mathrm{C}, 4)$. Upon chemisorption of the alkylsilane-based layer, features arising from the $\mathrm{C} 2 \mathrm{~s}$ and $\mathrm{C} 2 \mathrm{p}$ levels are detected (Figure 2C, $1-3)$. These features are highly reminiscent of those observed for straight chain alkanes. ${ }^{11}$

The RAIRS and XPS data collected for the silane-based layers support a proposed bonding geometry in which the alkyl chain remains intact and the $\mathrm{Si}$ atom forms three covalent bonds to the gold surface. Empirically, the simplest bonding geometries situate the Si atom either above the $\mathrm{Au} 3$-fold hollow or on top of one of the $\mathrm{Au}$ surface atoms as proposed for reactions of silanes with other metal surfaces. ${ }^{12,6 \mathrm{~b}}$

The RAIRS data for the silane-based layers are reminiscent of straight chain, thiol-based SAMs on gold. ${ }^{13}$ For example, the $v$ $(\mathrm{C}-\mathrm{H})$ features for $n$-octadecanethiol are observed at 2965, 2919, 2878 , and $2851 \mathrm{~cm}^{-1}$. The peaks correspond to the assignments of $v_{\mathrm{a}}\left(\mathrm{CH}_{3}\right), v_{\mathrm{a}}\left(\mathrm{CH}_{2}\right), v_{\mathrm{s}}\left(\mathrm{CH}_{3}\right)$, and $v_{\mathrm{s}}\left(\mathrm{CH}_{2}\right)$, respectively. ${ }^{14}$ The RAIRS spectra of octadecylsilane-based layers have features of similar intensity at $v_{\mathrm{a}}\left(\mathrm{CH}_{3}\right) 2968 \mathrm{~cm}^{-1}, v_{\mathrm{a}}\left(\mathrm{CH}_{2}\right) 2923 \mathrm{~cm}^{-1}$, and $v_{\mathrm{s}}\left(\mathrm{CH}_{2}\right)$ $2850 \mathrm{~cm}^{-1}$ (Figure 1A). The frequency of $v_{\mathrm{a}}\left(\mathrm{CH}_{2}\right)$ indicates that the alkyl chain for the silane-based monolayer is not as well packed as the alkyl chains of thiol-based SAMs. The $v_{\mathrm{s}}\left(\mathrm{CH}_{3}\right)$ feature has 

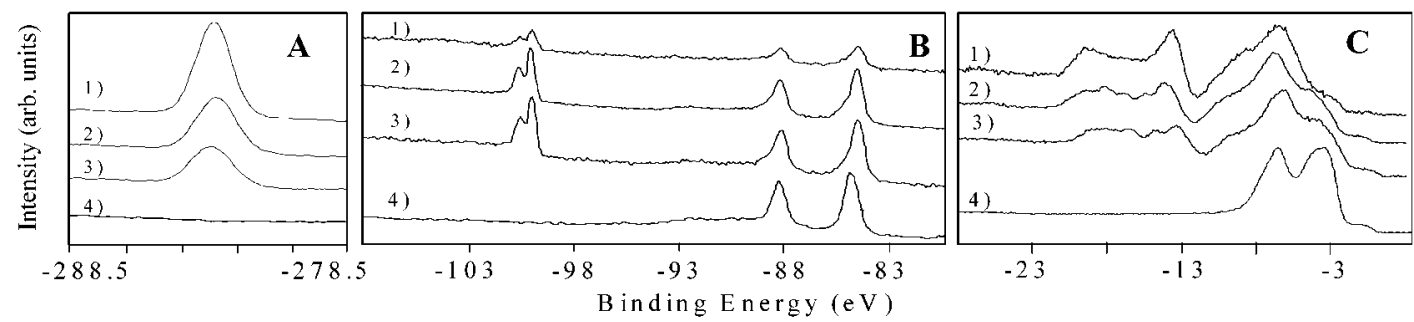

Figure 2. X-ray photoemission data for (A) C 1s core-levels, (B) Si 2p and Au $4 \mathrm{f}$ core-levels, and (C) the valence band region of (1) octadecylsilane, (2) octylsilane, and (3) hexylsilane chemisorbed on (4) freshly evaporated Au. The binding energies are referenced to Au $4 \mathrm{f}_{7 / 2}=-84 \mathrm{eV}$.

not been observed for the octadecylsilane monolayer. This may be a result of the position of the $\mathrm{CH}_{3}$ group with respect to the surface or simply signal-to-noise limitations. This feature is observed for the shorter chain alkylsilane-based layers; however, the $v_{\mathrm{a}}\left(\mathrm{CH}_{3}\right)$ mode is far more intense (Figure 1, B and C). Similar RAIRS comparisons between thiol ${ }^{15}$ and alkylsilane monolayers on gold can be drawn for the shorter chains. The ratio of the intensities of the $v\left(\mathrm{CH}_{3}\right)$ to $v\left(\mathrm{CH}_{2}\right)$ features decreases with increasing chain length. This is consistent with the decrease in the $\mathrm{CH}_{3}$ to $\mathrm{CH}_{2}$ ratio with increasing chain length in the alkyl chain.

Both RAIRS and XPS data strongly suggest the three $\mathrm{Si}-\mathrm{H}$ bonds of the alkylsilane are broken during the formation of these monolayers. Recall, the prominent $v(\mathrm{Si}-\mathrm{H})$ feature in the solution spectrum of the alkylsilanes is not observed for the monolayers (Figure 1). In addition, the binding energy observed in the XPS data is consistent with the loss of all three hydrogen atoms. For systems with $\mathrm{Si}-\mathrm{H}$ bonds, a shift of 0.3 to $1 \mathrm{eV}$ is observed in the Si $2 p$ core-levels, depending on the number of hydrogen atoms bound to the $\mathrm{Si}$ atom. ${ }^{16}$ These observations suggest that the silicon atom has formed three covalent bonds to the gold surface. The reaction may proceed by the oxidative addition of $\mathrm{Si}-\mathrm{H}$ bonds to the gold surface and the reductive elimination of $\mathrm{H}_{2} \cdot{ }^{17}$ The XPS and RAIRS data suggest the monolayers are chemically homogeneous. The chemical homogeneity of these monolayers is best assessed by the surprisingly narrow fwhm of $0.4 \mathrm{eV}$ for the Si $2 \mathrm{p}$ core-levels (Figure 2B). In addition to the previously described RAIRS correlation to the thiol case, this suggests that the $\mathrm{Si}-\mathrm{C}$ bond as well as the entire alkyl chain remains intact for the silanebased monolayers. The intensity of the Si $2 p$ core-levels diminishes with increasing alkyl chain length, as expected with exponential photoelectron attenuation (Figure 2B). Variable photon energy XPS has been shown to be sensitive to surface coverage. ${ }^{9}$ Using a range of photon energies $(160-400 \mathrm{eV})$, it has been determined that at least $95 \%$ of the $\mathrm{Au}$ surface is covered by the monolayer. ${ }^{18}$

The silanes do not form multilayers on gold surfaces at room temperature. If multilayers had formed, the silicon atoms would not be in a chemically homogeneous environment as suggested by the observed fwhms of the Si $2 p$ core-levels (Figure 2B). Furthermore, a second, more intense Si $2 p$ feature arising from silicon atoms not bonded directly to the gold surface would be observed. The binding energy of this core-level would be several electronvolts higher due to the hydrogen atoms on the silicon, sample charging, and a greater influence from final state effects than those experienced by the $\mathrm{Si}$ atoms bound directly to the surface. In addition, the intensity of the Au $4 \mathrm{f}$ and the observed Si 2p core-levels would be attenuated by the presence of the multilayers.

All three alkylsilane monolayers are stable to $>36000 \mathrm{~L} \mathrm{H}_{2} \mathrm{O}$ or $\mathrm{O}_{2}$ exposure. However, exposure to ambient conditions results in the oxidation of the silicon atoms as judged by a $2.3 \mathrm{eV}$ shift in the $\mathrm{Si} 2 \mathrm{p}$ core-level. Similar instabilities, ascribed to reactions with ozone, have been noted for alkanethiol systems. ${ }^{19}$ The oxidized monolayers are stable to water, methanol, and $n$-hexane rinses as judged by conventional XPS.

In conclusion, alkylsilanes form monolayers on freshly evaporated gold surfaces in UHV. The silane remains intact on the gold surface, likely forming three covalent $\mathrm{Au}-\mathrm{Si}$ bonds by means of $\mathrm{Si}-\mathrm{H}$ bond activation. It is envisioned that control of the number of $\mathrm{Au}-\mathrm{Si}$ bonds could be attained by the use of di- and trisubstituted silanes. This may permit a unique tailoring of the monolayer's functional properties via selection of a specific bonding geometry.

Acknowledgment. Dow Corning and the NSF (DMR-0093641 and INT-0096583) are thanked for their support. The research was carried out (in part) at the National Synchrotron Light Source, Brookhaven National Laboratory, which is supported by the U.S. Department of Energy, Division of Materials Sciences and Division of Chemical Sciences. S.S. is grateful for the support of a FullbrightFellowship. M.M.B.H. appreciates the support of an Alfred P. Sloan Research Fellowship. J. Kulman is thanked for the initial evaporation of the Au onto the Si. We thank Dr. K. Z. Zhang for assistance at U8B.

Supporting Information Available: Materials and experimental procedures (PDF). This material is available free of charge via the Internet at http://pubs.acs.org.

\section{References}

(1) (a) McDermott, M. T.; Green, J.-B. D.; Porter, M. D. Langmuir 1997, 13, 2504. (b) DePalma, V.; Tillman, N. Langmuir 1989, 5, 868.

(2) (a) Laibinis, P. E.; Bain, C. D.; Nuzzo, R. G.; Whitesides, G. M. J. Phys. Chem. 1995, 99, 7663. (b) Shon, Y.-S.; Lee, S.; Colarado, R., Jr.; Perry, S. S.; Lee, T. R. J. Am. Chem. Soc. 2000, 122, 7556.

(3) Nuzzo, R. G.; Allara, D. L. J. Am. Chem. Soc. 1983, 105, 4481.

(4) (a) Ulman, A. Chem. Rev. 1996, 96, 1533. (b) Schreiber, F. Prog. Surf Sci. 2000, 65, 151 .

(5) Dannenberger, O.; Weiss, K.; Himmel, H.-J.; Jäger, B.; Buck, M.; Wöll, C. Thin Solid Films 1997, 307, 183 .

(6) (a) Bradshaw, D. I.; Moyes, R. B.; Wells, P. B. J. Chem. Soc., Faraday Trans. 1 1980, 76, 979. (b) Wiegand, B. C.; Lohokare, S. P.; Nuzzo, R. G. J. Phys. Chem. 1993, $97,11553$.

(7) Fadeev, A. Y.; McCarthy, T. J. J. Am. Chem. Soc. 1999, 121, 12184

(8) (a) Nicholson, K. T.; Zhang, K. Z.; Banaszak Holl, M. M. J. Am. Chem. Soc. 1999, 121, 3232. (b) Nicholson, K. T.; Zhang, K. Z.; Banaszak Holl, M. M.; McFeely, F. R.; Pernisz, U. C. Langmuir 2000, 16, 8396.

(9) Lamont, C. L. A.; Wilkes, J. Langmuir 1999, 15, 2037.

(10) Heister, K.; Zharnikov, M.; Grunze, M.; Johansson, L. S. O.; Ulman, A. Langmuir 2001, 17, 8.

(11) Pireaux, J.-J.; Caudano, R. Phys. Rev. B 1977, 15, 2242.

(12) Hostetler, M. J.; Nuzzo, R. G.; Girolami, G. S. J. Am. Chem. Soc. 1994, $116,11608$.

(13) (a) Nuzzo, R. G.; Dubois, L. H.; Allara, D. L. J. Am. Chem. Soc. 1990 , 112, 558. (b) Laibinis, P. E.; Whitesides, G. M.; Allara, D. L.; Tao, Y.T.; Parikh, A. T.; Nuzzo, R. G. J. Am. Chem. Soc., 1991, 113, 7152.

(14) Assignments from ref 13a

(15) Porter, M. D.; Bright, T. B.; Allara, D. L.; Chidsey, C. E. D. J. Am. Chem. Soc. 1987, 109, 3559.

(16) Karlsson, C. J.; Landemark, E.; Johansson, L. S. O.; Karlsson, U. O. Uhrberg, R. I. G. Phys. Rev. B 1990, 41, 1521.

(17) Stobinski, L.; Dus, R. Vacuum 1994, 45, 299.

(18) Owens, T. M.; Süzer, S.; Banaszak Holl, M. M. To be submitted for publication.

(19) Schoenfisch, M. H.; Pemberton, J. E. J. Am. Chem. Soc. 1998, 120, 4502. JA025755F 